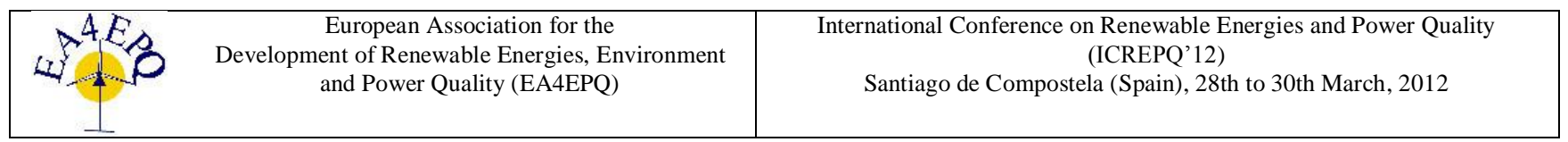

\title{
Dimension and production of a turbine type francis
}

\author{
Elmo Thiago Lins Cöuras Ford ${ }^{1}$, Ana Catarina Mendes Barradas ${ }^{2}$, José Ubiragi de Lima Mendes ${ }^{3}$, Rubens \\ Maribondo do Nascimento 3 \\ ${ }^{1}$ Universidade do Porto / Universidade Federal do Rio Grande do Norte, elmocouras@ hotmail.com \\ ${ }^{2}$ Universidade de Coimbra - UC, catarina-barradas@hotmail.com \\ ${ }^{3}$ Universidade Federal do Rio Grande do Norte - UFRN, ubiragi@ct.ufrn.br; rmaribondo@ufrnet.br
}

\begin{abstract}
Now in Brazil, most of the produced electric power and originating from hydroelectric that for your time are used of hydraulic turbines to transform the hydraulic energy (the pressure energy and the kinetic energy) of a flow of water, in mechanical energy and for your time in electric power. However they can also be used for generation of energy in small scale, for the isolated communities. In that way, this work looked for dimension and to manufacture a turbine of the type Francis in kindred scale of being used in small communities.
\end{abstract}

\section{Key words}

Turbines Francis, Hydraulic energy, Small hydroelectric.

\section{Introduction}

The turbines Francis was idealized in 1849, tends your inventor's name, and the first turbine was built by the firm J.M. Voith in 1873, ever since going by constant improvements, as the use of the shovels guidelines, also calls of shovels Fink (HENN, 2003).

The turbine Francis, considered a reaction turbine, in other words, it works with a pressure difference among the two sides of the rotor. The shovels of the rotor are profiled in a complex way, they are usually melted.

In operation, the water enters in the rotor for the periphery, after passing through the shovels guidelines which guide the liquid in an appropriate angle for the entrance of the shovels of the rotor, leaving the same axial in relation to the axis.

\section{Theory}

The turbines Francis can be executed so much with axis in the horizontal as in the vertical. The construction with axis in the horizontal, in other words, the wheel working vertically is used for small units, in that case supported in you limp of radial sliding and it spares the use of you limp guides, used when the construction is of vertical axis.
The turbines modern Francis is always adjusted also with the shovels guidelines dealers' calls, and the same ones are commanded by the group regulator that you/they adjust the flow to the load of the turbine.

The rotor of the turbine Francis of small and medium sizes can be built in only one he totally asks melted. The material used it is usually the steel melted with 12 to $15 \%$ of chrome, but in some cases it is built in stainless steel. Depending on the expected size for the rotor, motivated by a great project flow, can calculate an only turbine being used of a double rotor (couple suction). Such construction, however, it is only viable for the turbine working with axis in the horizontal. (HENN, 2003).
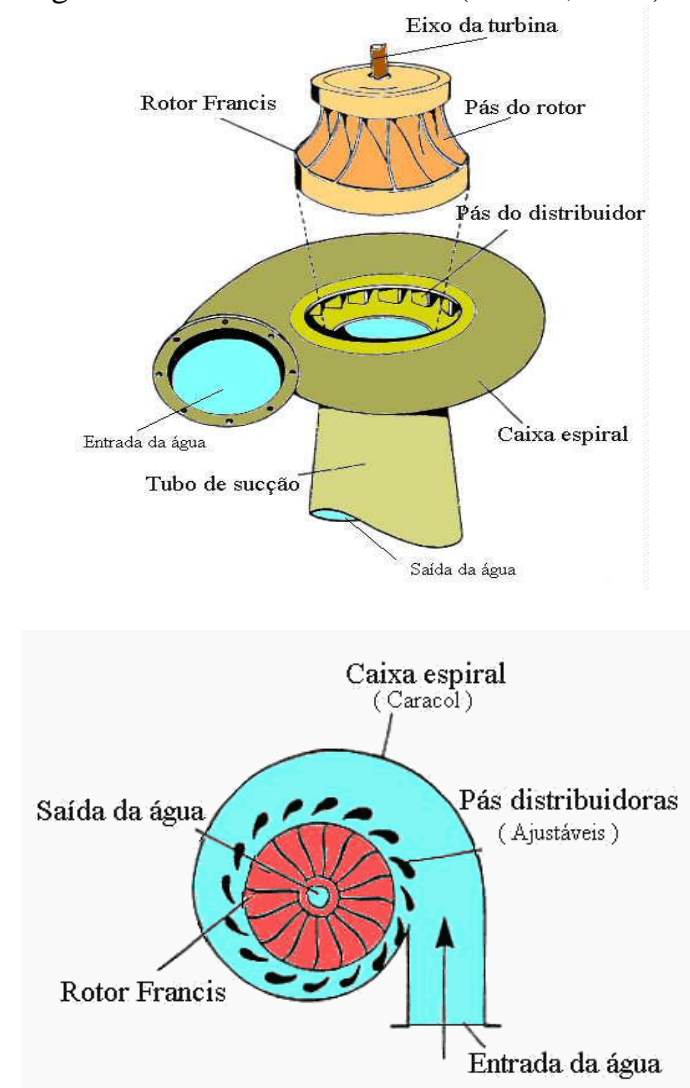

Figure 1. Draw of the outline of operation of a turbine. 
Second Viana (1997), the turbines Francis is used in uses with falls above $10 \mathrm{~m}$, could be said that is, of all the turbines, the most electric. Two types of turbines exist Francis:

- Francis open box: advisable for hydroelectric uses with fall up to $10 \mathrm{~m}$. The rotor, the distributor, the aspiration tube and it leaves of the axis they are inside located of a camera in direct communication with the load camera and below the minimum level of amount. The axis can be horizontal or vertical.

- Francis spiral box: for falls above $10 \mathrm{~m}$. For the small central chaos the axis is willing horizontal, due to the installation means and maintenance.

The turbines Francis can still be classified, according to the specific speed in:

Slow - exit diameter sensibly smaller than the one of entrance.

Normal - entrance diameter and exit are same.

Fast - diameter of larger exit than the one of the entrance.

Very fast - the board of entrance of the shovels is much tilted to the axis that gives characteristics.

\section{Results}

\subsection{Calculation of a turbine Type Francis}

In this work it was dimension a turbine Francis for a flow $Q=20 \mathrm{~m}^{3} / \mathrm{s}$, a specific work $Y=410 \mathrm{~J} / \mathrm{kg}$, and to be installed at a place where the height is of $430 \mathrm{~m}$.

\subsection{Potencies}

- Hydraulic potency $P_{1}$ :

$P_{1}=Q \times \rho \times Y=20 \times 1.000 \times 410=8,2 \times 10^{3} \mathrm{KW}$

Being adopted $\mathrm{n}_{\mathrm{t}}=0,79$ and $\mathrm{n}_{\mathrm{m}}=0,92$ soon $\mathrm{n}_{\mathrm{h}}=0,85$

- Effective potency $P_{2}$ :

$$
P_{2}=P_{1} \times n_{t}=8,2 \times 0,79=6,5 \times 10^{3} \mathrm{KW}
$$

\subsection{Choose of the turbine type}

The choice of the rotor was made with base in the specific rotation and in the maximum height of installation given by the formulas $n_{q A}=n \times \frac{Q^{1 / 2}}{Y^{3 / 4}} \times 10^{3} \quad$ and $h_{s_{\max }}=\frac{1}{g} \times\left(\frac{P_{B}}{\rho}-\sigma_{\min }\right)$ respectively. With aid of the figure 2 , a table 1 is set up with the choice elements.

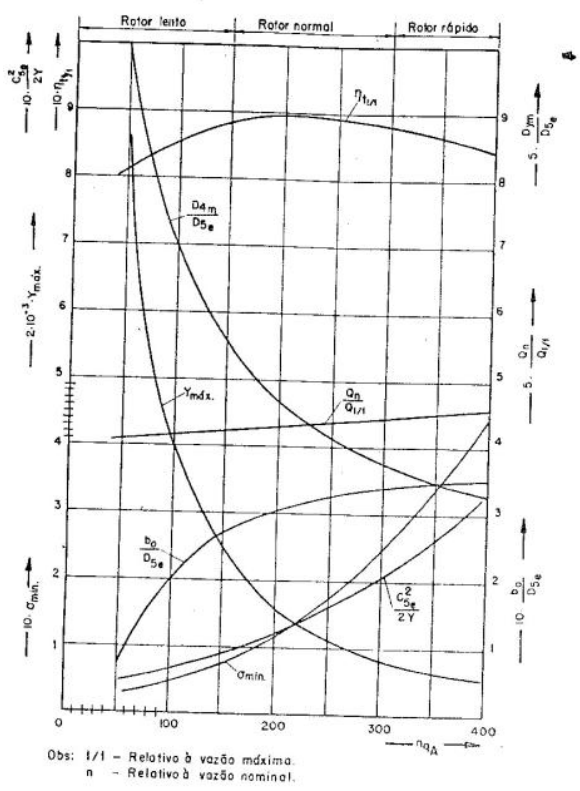

Figure 2. Elements for pre-dimension of rotors Francis. (HENN, 2003)

Table 1. Elements for choice of the rotor.

\begin{tabular}{|c|c|c|c|c|c|}
\hline$n^{\prime}$ & $n$ & $n_{q A}$ & $\sigma_{\text {min. }}$ & $50 \times \sigma_{\text {min. }}$ & $h_{s_{\text {max }}}$ \\
\hline RPM & RPS & - & - & $\mathrm{M}$ & $\mathrm{M}$ \\
\hline 400 & 6,66 & 313 & 0,26 & 13,0 & $-3,59$ \\
\hline 360 & 6,00 & 282 & 0,23 & 11,0 & $-1,59$ \\
\hline 300 & 5,00 & 235 & 0,16 & 8,0 & 1.41 \\
\hline 200 & 3,30 & 155 & 0,08 & 4,0 & 5,41 \\
\hline
\end{tabular}

In this work a rotation of 5,00 rps was used and therefore the specific rotation will:

$$
n_{q A}=n \times \frac{Q^{1 / 2}}{Y^{3 / 4}} \times 10^{3}=n_{q A}=5 \times \frac{20^{1 / 2}}{410^{3 / 4}} \times 10^{3}=235,
$$

this way the turbine Francis had been classified as fast.

\subsection{Orientation elements for the rotor}

Of the figure 2, obtain:

$$
\frac{C_{5_{\max }}^{2}}{2 \times Y}=0,16 ; \quad \frac{D_{4_{m}}}{D_{5_{e}}}=0,79 ; \quad \frac{b_{0}}{D_{5_{e}}}=0,32
$$

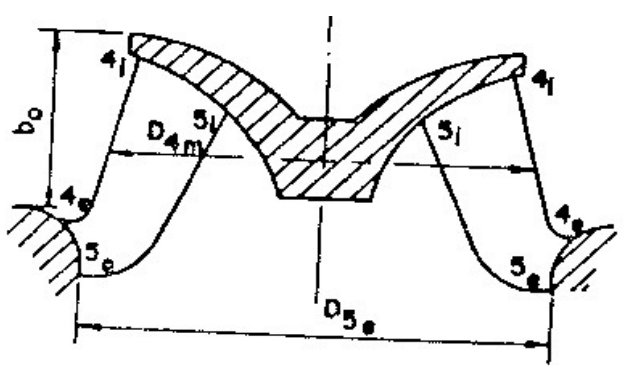

Figure 3. Elements of orientation of the rotor. 


$$
\begin{aligned}
& C_{5_{\text {máx }}}=\sqrt{0,16 \times 2 \times Y}=\sqrt{0,16 \times 2 \times 410}=11,45 \mathrm{~m} / \mathrm{s} \\
& D_{5_{e_{\text {min. }}}}=\sqrt{\frac{4 \times Q}{\pi \times C_{5_{\text {max }}}}}=\sqrt{\frac{4 \times 20}{\pi \times 11,45}}=1,5 \mathrm{~m} \\
& D_{4_{m}}=0,78 \times D_{5_{e}}=D_{4_{m}}=0,78 \times 1,5=1,17 \mathrm{~m} \\
& b_{0}=0,31 \times D_{5_{e}}=b_{0}=0,31 \times 1,5=0,465 \mathrm{~m}
\end{aligned}
$$

\subsection{Verification of the established elements for the rotor}

Verifying the fundamental equation of the turbines.

$$
\begin{aligned}
& u_{4_{m}}=\pi \times D_{4_{m}} \times n=\pi \times 1,17 \times 5=18,37 \mathrm{~m} / \mathrm{s} \\
& Y_{p a}=n_{h} \times Y=0,84 \times 410=348,5 \mathrm{~J} / \mathrm{Kg}
\end{aligned}
$$

Arbitrated a triangle of speeds with tendency the fast, $\beta_{4}=80^{\circ}$ and e $C u_{4_{m}}=17 \mathrm{~m} / \mathrm{s}$

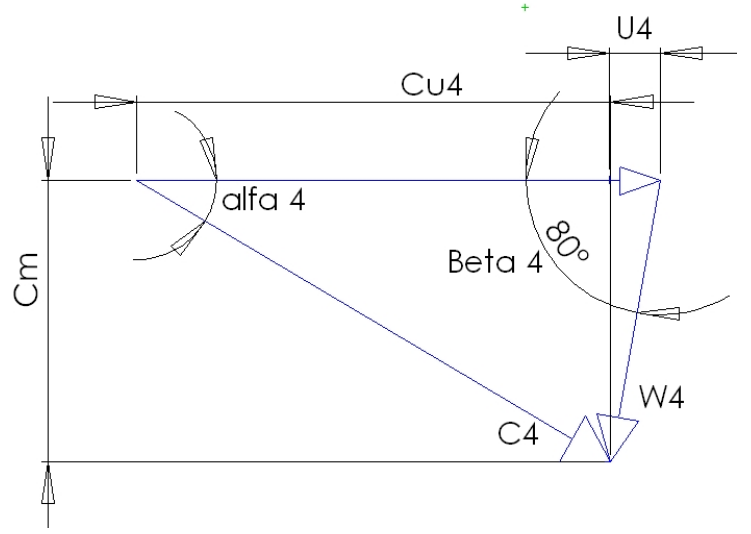

Figure 4. Arbitrated triangle.

$Y_{p a ́}=11,45 \times 17=195 \mathrm{~J} / \mathrm{Kg}, Y_{p a ́}=348 \mathrm{~J} / \mathrm{Kg}$ and $u_{4_{m}}$.

$Y_{p a ́}=u_{4}^{2} \times \frac{C u_{4 m}}{u_{4_{m}}}=u_{4_{m}}^{2} \times n_{1} ; \log 0 \quad u_{4_{m}}=\sqrt{\frac{Y_{p a ́}}{n_{1}}}$

$n_{1}=0,92, u_{4_{m}}=\sqrt{\frac{348}{0,92}} ; u_{4_{m}}=19,45 \mathrm{~m} / \mathrm{s}$ and

$C u_{4_{m}}=17,9 \mathrm{~m} / \mathrm{s}$

$D_{4_{m}}=\frac{u_{4_{m}}}{\pi \times n}=\frac{19,45}{\pi \times 5}=1,24 m ; \quad D_{4_{m}}=0,78 \times D_{5_{e}}=$

$D_{5_{e}}=\frac{1,24}{0,78}=1,58 m$

For the equation of the continuity obtains:

$$
\begin{aligned}
& C_{5}=\frac{4 \times Q}{\pi \times D_{5}^{2}}=C_{5}=\frac{4 \times 20}{\pi \times 1,58^{2}}=10,2 \mathrm{~m} / \mathrm{s} ; \\
& b_{0}=0,31 \times 1,58=0,49 \mathrm{~m}
\end{aligned}
$$

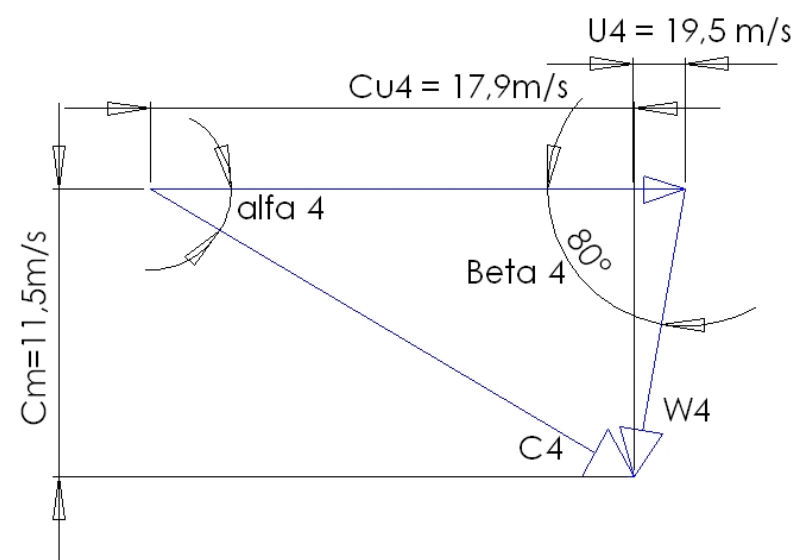

Figure 5. Triangle of speed for a medium thread in the entrance.

\subsection{Triangles of speed for the entrance edge}

$\ln \frac{C m_{y}}{C m_{4 i}}=\frac{y}{\mu \times r_{1}} \times\left[1+\frac{y}{2 \times L}\left(\frac{r_{1}}{r_{2}}-1\right)\right]$

Divided the entrance edge in four parts, tends therefore each one $\frac{697}{4}=174 \mathrm{~mm}$ :

$$
\begin{array}{ll}
y_{1}=174 \mathrm{~mm} & y_{2}=348 \mathrm{~mm} \\
y_{3}=522 \mathrm{~mm} & y_{4 e}=697 \mathrm{~mm}
\end{array}
$$

$\ln \frac{C m_{y}}{C m_{4 i}}=\frac{y}{5 \times 550} \times\left[1+\frac{y}{2 \times 697}\left(\frac{550}{155}-1\right)\right]$

$y_{1}=174 m m ; \quad \frac{C m_{1}}{C m_{4 i}}=1,0875$

$y_{2}=348 m m ; \quad \frac{C m_{2}}{C m_{4 i}}=1,230$

$y_{3}=522 \mathrm{~mm} ; \quad \frac{\mathrm{Cm}}{\mathrm{Cm}} \mathrm{Cm}=1,451$

$y_{4 e}=697 \mathrm{~mm} ; \quad \frac{C m_{4 e}}{C m_{4 i}}=1,782$ 
$y_{1}=174 m m$

$\frac{C m_{1}}{C m_{4 i}} \times D_{1}=1,087 \times 1,33=1,445 m$

$y_{2}=348 m m$

$\frac{C m_{2}}{C m_{4 i}} \times D_{2}=1,230 \times 1,36=1,675 m$

$y_{3}=522 \mathrm{~mm}$;

$\frac{C m_{3}}{C m_{4 i}} \times D_{3}=1,451 \times 1,43=2,080 m$

$y_{4 e}=697 \mathrm{~mm}$;

$\frac{C m_{4}}{C m_{4 i}} \times D_{4}=1,782 \times 1,69=3,105 m$

$Q_{n}=0,86 \times 20=17,2 m^{3} / s$

$C m_{4 i}=\frac{Q_{n}}{\pi \times \sum y \times D_{y} \times \frac{C m_{y}}{C m_{4 i}}}=\frac{17,2}{\pi \times 1,3}=4,31 \mathrm{~m} / \mathrm{s}$

$C m_{4 i}=\frac{4,31}{0,9}=4,74 \mathrm{~m} / \mathrm{s}$

\subsection{Triangles of speed for exit edge}

$C m_{5}=\frac{4 \times Q_{n}}{\pi \times D_{5 e}^{2}}=\frac{4 \times 17,2}{\pi \times 2,49}=8,8 \mathrm{~m} / \mathrm{s}$,

$C m_{5}=\frac{8,8}{0,97}=9,07 \mathrm{~m} / \mathrm{s}$,

$D_{x} \times Y_{x}=\frac{Q_{n}}{4 \times \pi \times C m_{5}}=\frac{17,2}{4 \times \pi \times 9,07}=0,1817$

$D_{I V} \times Y_{I V}=1,622 \times 0,133=0,187$

$D_{\text {III }} \times Y_{\text {III }}=1,35 \times 0,135=0,182$

$D_{\text {II }} \times Y_{\text {II }}=1,035 \times 0,18=0,184$

$D_{I} \times Y_{I}=0,75 \times 0,243=0,182$



Figure 6. Generic triangle of speeds.

Table 3. Elements for the plan of the triangles of speed for the exit edge.

\begin{tabular}{|l|l|l|l|l|}
\hline PTS & $D_{y}$ & $u_{5_{y}}$ & $\operatorname{tg} \beta_{5_{y}}$ & $\beta_{5_{y}}$ \\
\hline--- & $M$ & $m / s$ & --- & Graus \\
\hline $5_{i}$ & 0,65 & 10,2 & 0,885 & $41^{\circ} 30^{\prime}$ \\
\hline$I$ & 0,75 & 11,78 & 0,765 & $37^{\circ} 25^{\prime}$ \\
\hline$I I$ & 1,035 & 16,23 & 0,555 & $29^{\circ} 03^{\prime}$ \\
\hline$I I I$ & 1,35 & 21,20 & 0,425 & $23^{\circ} 02^{\prime}$ \\
\hline$I V$ & 1,622 & 25,45 & 0,364 & $19^{\circ} 30^{\prime}$ \\
\hline 5 & 1,73 & 27,18 & 0,332 & $18^{\circ} 03^{\prime}$ \\
\hline
\end{tabular}

\subsection{Spiral}

To increase the energy of the water before reaching in the rotor, a managing system, ace is used times composed of a spiral and of a system of slats. As it can be observed in the fig. 7 and 8.

Detalhe interno do anel de regulagem e pass diretrizes.

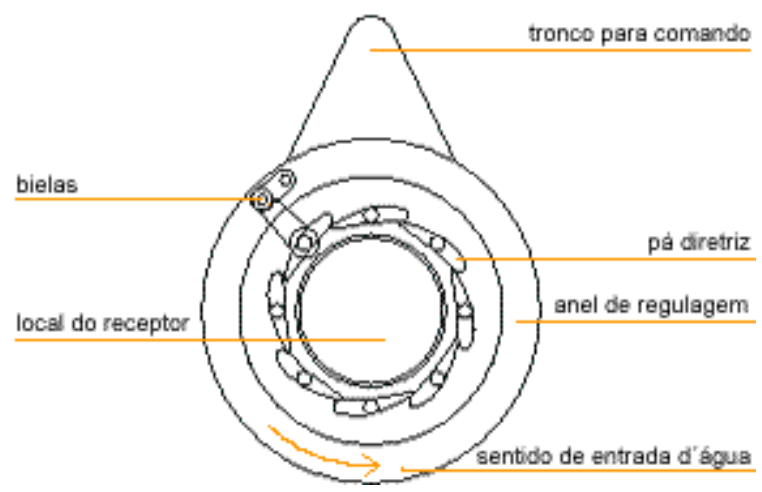

Figura 7. Outline of the shovels guidelines. 


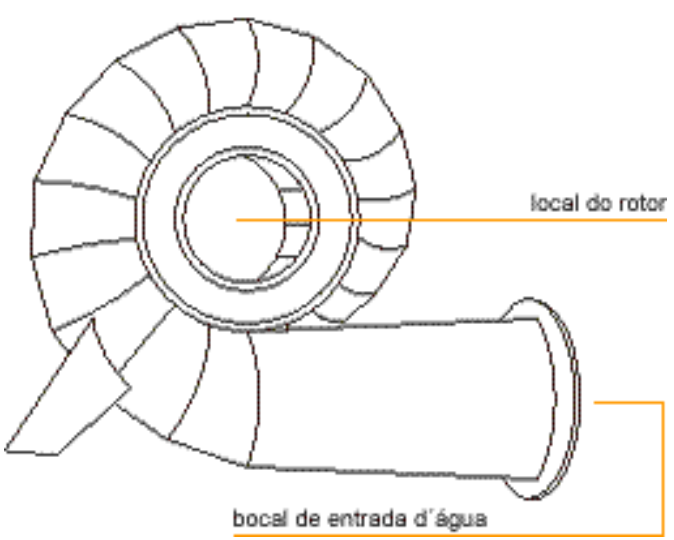

Figura 8. Snail of the turbine Francis.

$C_{E}=(0,15 a 0,25) \times \sqrt{2 \times Y}$.

$C_{E}=0,20 \times \sqrt{2 \times 410}=5,72 \mathrm{~m} / \mathrm{s}$

$D_{E}=\sqrt{\frac{4 \times Q_{n}}{\pi \times C_{E}}}=\sqrt{\frac{4 \times 17,2}{\pi \times 5,72}}=1,95 \mathrm{~m}, C_{E}^{\prime}=C_{E}:$

$C_{E_{m}}^{\prime}=\frac{4 \times Q_{n}}{\pi \times D_{E}^{\prime 2}}, D_{E}^{\prime}=1,6 m$

$C_{E_{m}}^{\prime}=\frac{4 \times 17,2}{\pi \times 2,56}=8,56 \mathrm{~m} / \mathrm{s}$

$r_{1 d}=1200 \mathrm{~mm}$

$K_{1 d}=\left(r_{1 d}+D_{E}^{\prime}\right) \times C_{E}^{\prime}=(1.280+1,6) \times 5,76=16,5 \mathrm{~m} / \mathrm{s}$

$K_{r}=C u_{4 m} \times r_{4 m}=\frac{n_{h} \times Y}{2 \times \pi \times n}=\frac{0,85 \times 410}{2 \times \pi \times 5}=11,1 \mathrm{~m} / \mathrm{s}$

$R=\frac{\theta}{A}+\sqrt{\frac{2 \times r_{1 d} \times \theta}{A}}, Q=Q_{n}$

$A=\frac{720 \times 16,5 \times \pi}{17,5}=2130$

Table 4. Elements of the spiral

\begin{tabular}{|l|l|}
\hline$\theta$ & $R_{\text {metvos }}$ \\
\hline 45 & 0,253 \\
\hline 90 & 0,380 \\
\hline 135 & 0,505 \\
\hline 180 & 0,545 \\
\hline 225 & 0,635 \\
\hline 270 & 0,710 \\
\hline 315 & 0,776 \\
\hline 360 & 0,837 \\
\hline
\end{tabular}

\subsection{Elements of the spiral}

In that way, the entrance angles and exit of the system of shovels guidelines are calculated

$$
\begin{aligned}
& \operatorname{tg} \alpha_{1}=\frac{C_{m}}{C u_{1}} ; \quad C u_{1}=\frac{K_{e s p .}}{r_{1}}, \\
& C_{m}=\frac{Q_{n}}{\pi \times D_{1} \times b_{0} \times 0,9} \\
& \operatorname{tg} \alpha_{1}=\frac{17,5}{2 \times \pi \times 0,47 \times 0,9 \times 16,5}=0,399 ;
\end{aligned}
$$

$\alpha_{1}=21,75^{\circ}$

$$
\begin{aligned}
& \operatorname{tg} \alpha_{2}=\frac{17,5}{2 \times \pi \times 0,47 \times 0,9 \times 11,1}=0,593 ; \\
& \alpha_{1}=30,67^{\circ}
\end{aligned}
$$

\section{Conclusion}

The turbines Francis is one of the spread and used in so much Brazil for big as for small, mini and personal computer-central hydroelectric. It has been applied broadly, for the fact of your characteristics they cover a great field of specific rotation. Now they are built for great uses, could surpass the unitary potency of $750 \mathrm{MW}$. The turbines built among 1930 to 1950 they didn't possess superior revenues to $85 \%$, today they surpass to $92 \%$ for great machines. One of the only disadvantages of the turbines type Francis and that it can also be verified in this project, it was the variation of the revenue curve with the flow.

\section{Acknowledgement}

PPGEM/UFRN; ULBRA; CAPES; CNPQ.

\section{References}

[1] HENN, E.A.L. Máquinas de fluxo. Editora UFSM, 2003.

[2] MACINTYRE, A.J. Máquinas motrizes hidráulicas. Rio de Janeiro: Guanabara Dois, 1983. 654 p.

[3] PFLEIDERER,C.PETERMANN, H. Máquinas de fluxo. Editora S/A. Rio de janeiro, 2004.

[4] RICHARD BRAN, Z. S. Maquínas de fluxo: bombas turbinas e ventiladores. Rio de Janeiro: livro técnico, 1980.

[5] SOUZA, Z.; VIANA, A.N.C. Bombas funcionando como turbinas. Itajubá: Escola Federal de Engenharia, 198-. 19 p.

[6] VIANA, A.N.C. Pequenas centrais hidrelétricas no meio rural. In: SERAPHIM, O.J. (Ed.) Tecnologia e aplicação racional de energia elétrica e de fontes renováveis. Campina Grande: SBEA/UFPB, 1997.p.135-64.

[7] VIANA, A.N.C.; LEITE, F. Bombas centrífugas funcionando como turbinas, para microcentrais. Mundo Elétrico, São Paulo, n.320, p.52-5, 1986. 